\title{
Analysis of the Influence of Migrant Socioeconomic Factors to the Criminal Behavior at the Surabaya City
}

\author{
Eko Nur Wahyudiono ${ }^{1}$, M. Pudjihadjo ${ }^{2}$, Khusnul Ashar ${ }^{2}$, Susilo $^{2}$ \\ Faculty of Economics and Business, Brawijaya University, East Java, Indonesia
}

\begin{abstract}
The research aimed at knowing the socioeconomic conditions of criminals after migrated to Surabaya City, Indonesia, and analyze the socioeconomic factors to the emergence of criminal behavior.

To know the social condition and the causing social factors of criminal behavior, then the research used qualitative approach that aims to dig the real meaning about the conditions and causing social factors of the criminal behavior.

The research informants is the criminal migrants of 74 persons, at the custody of East Java Regional Police, City Police of Surabaya, and City Police of Tanjung Perak Port.

The results showed that the socio economic conditions of the doers after migrated to Surabaya City is constant, because of interested in the urban culture that more modern to the rural area, and expect able to change their appearance and have urban characters, while the migrant's life standard that decrease because do not have skill to get job. In the mean time, the socio economic factors of migrant that cause the criminal behaviors because only graduated from Senior High Schools /Aliyah that were not vocational education so do not have skills to get job, the emergence of disappointment in reaching the welfare, the criminal behaviors do not consider the religious precepts, moderate job sustainability with low income, difficulty in finding a job because of less job place availability, intense competition, many dependents out of family, influenced by milieu .
\end{abstract}

Keywords: migrant, criminality, socio economic

\section{Introduction}

Concentration of economic activities and higher urban competitiveness compared with around area, does not make the city free from the economic, social and environmental problems. Characteristic that showed heavy burden of urban area is shown by urbanization, unemployment, wide slum, high criminality and etc. The high economic activities of city in one side and followed by the increasing social, economic, and environmental problems, in other side showed the urban paradox indications (OECD, 2006), where the condition in the long term able to influence the urban competitiveness.

Conflict in the society is determined by groups, based on their interest and perception toward the conflict and usually the interest conflict is created in the process of law making. According to radical group, there are two things that cause group, that is interest struggle and perception to the conflict. Usually, interest conflict is created in the law making. First, they consider that their groups are the tool of the ruling class. The definition of crime in the law is the reflection of capitalism concept. While the ruling class behavior in general is not placed under the criminal law. Second, the radical group look all crimes as the results of group struggle that is the reflection of individualism and competition. At the end discussion about radical conflict, Richard Quinny and Steven Spitzer, 1975 (in Putnam, 1995) discussed about the excessive of labor amount as problem in the capitalistic society. The excessive labor will cause low wage, but extreme excessive labor will cause problems.

Indonesian population from data of criminal situation of National Police Headquarter of 2006 of 213.299 .510 , tend to increase compared in the 2005 of 208.198.533. It impacted the total crime of 2005 of 226.890 cases. While the vulnerability level of Regional Police based on report of 2005, East Java Regional Police gets vulnerability of ranking II pf 26.250 criminal cases, while the Metro Regional Police at the ranking I of 57.762 criminal cases.

There are some groups or occurred prominent crimes such as: robbing with weighting down, motor vehicle theft, fraud, heavy molestation, gambling, murder, fire, drugs, timber theft, rape, firearm / explosive, fake letter, counterfeit money, and environmental destruction.

Thus, the research goals are:

1. To know the socio economic conditions of the criminals after migrated to Surabaya City. 
2. To analyze the socio economic factors of migrant toward the criminal behavior emergence.

\subsection{Migration theory}

\section{Literature Review}

Economic theory about rural-urban migration was stated by Todaro (2003), that the migration flow occurs as the response to the different income between urban and rural area. They will migrate if the net income in the city is higher then in the village.

The Todaro migration model (2003) had four basic thoughts as follow:

1. Rural-urban migration is stimulated especially by the rational economic consideration that occurs that relate with the profit or benefit and relative cost of the migration.

2. Decision to migrate depend on the difference between the expected income in the city and the actual income in the village.

3. Possibility to get job in the city that relate directly with the jobs in the rural area, so inversely with the urban unemployment.

The migration from the poor area to the rich area not limited at the man powers, but also the capital at the poor area. The capital will flow from poor to the rich area. According to Hirchman (1958), economic development is considered geographically as not balanced, not spread evenly in all directions. Initially, the economic development will be centered in some areas. Because of that, in a country, its area can be divided into two areas, rich and poor area. In the development process, the differences become wider because there are some factors that cause the poor area difficult to develop relatively. According to Hirchman, the factor called as trickle down effect and polarization effect.

\subsection{Basic theory of criminal}

Criminality term has been viewed from different viewpoints. Some have equated it with sin or lie, and other definition states it as danger behavior or deviant behavior from the social norm. The sociologists considered the crime as unlawful actions. However, if the crime is defined as the law violation, civil servants and politician are permitted to value it from the social foundation and the scientific concept.

According to Sutherland (1949), there are some crime types, such as:

1. White collar crime, crime that is done by respectable persons, that have high social status in his work. White collar cost three times than other crimes, including against the law, money embezzlement, price fixing, industrial safety violation, and representation mistake of advertising.

2. Organized crime, all activities from all groups with hierarchic organization, where the members do illegal business or with illegal power.

3. Juvenile crime become extraordinary concerns in the modern society. Some countries react with frustration to the juvenile crime, for example the increasing number of juvenile crime.

\subsection{Relationship between criminality and economic modernization}

The most reliable and popular social control theory stated by Travis Hirschi, 1969 (in Atmasasmita, 2005) about social bond concept. Hirschi sure that the someone behavior is the reflection of various viewpoint about ethics. His opinion is someone free to do crime or deviant behavior because there is no relation or less moral relation of the doer to the society.

\subsection{Relationship between crime and unemployment}

John Hagan (1998) stated in the macro analysis, his attention more directed to the unemployment as the causes of the crime. In contrary in the micro analysis, the possibility that will be studied is the contrary condition, that is the relationship analysis between the criminal action and the unemployment emergence.

At the micro analysis, Hagan (1998) stated the criminal action is one of factors that have roles in the occurrence of unemployment. The juvenile crime usually is action that occurred earlier in the individual life spans and ended when the individual reached mature and then become unemployment. Hagan tried to analyze the causality relationship between crime as the causes and the unemployment as the consequences. 


\section{Results And Discussion}

The research focuses on the migrant criminals with socio economic motives. It is along with the view that human being more as homo sociologicus that give emphasis to the interaction or behavior that is more individual and not give emphasis to the institutional environment or the rule of games, that impact to the behavior and performance of economic player.

The informant experiences in getting the last job, $27.2 \%$ stated as easy, $48.8 \%$ stated as rather difficult to get job and $24.24 \%$ stated as difficult to get job. The informant difficulty in getting job because of the less job location availability, intense competition, low education that influence the low skill for work.

Unemployment is individual that enter into workforce (15 to 64 years old) that finding for job and not getting yet. Individual that is not finding for job for example housewife, junior and senior high schools students, university students, and etc because of something they do not /yet need job.

Informants do not have job of 8 persons, because lack of skills $37.5 \%$, while the $62.5 \%$ informants do not have job because as the housewife, new graduate, retired, and follow their children.

Beside husband, wife, and children the respondents have many other dependents such as parents/parent in law, and nephew. From the average of the respondent's dependents between 1-6 persons out of their family. It showed the many dependents indicated the many expenditures to fulfill the living needs than those with less dependents. The more dependents the more economic burden of the respondents, that will impact to the criminal behavior of the respondents. The difficulty in fulfilling the living needs will have great impact to the informant family.

Table 3.1

The dependents amount of informant beside husband/wife and children

Source: processed data, 2012

\begin{tabular}{|l|l|l|l|}
\hline No & $\begin{array}{l}\text { Dependents beside } \\
\text { husband/wife/children }\end{array}$ & Amount & $\%$ \\
\hline 1 & 1 & 3 & 21.43 \\
\hline 2 & 2 & 3 & 21.43 \\
\hline 3 & 3 & 2 & 14.29 \\
\hline 4 & 4 & 4 & 28.57 \\
\hline 5 & 5 & 1 & 7.14 \\
\hline 6 & 6 & 1 & 7.14 \\
\hline \multicolumn{2}{|l|}{} \\
\hline
\end{tabular}

The modernization of attitude shifting process and mentality as the societal members to be able live with today demand. According to Widjojo Nitiastoro (in Rahardi 2012), modernization is total transformation from traditional life pre modern in the technological term and social organization to the economic and political pattern (Rahardi 2012). In here it will be continued the modernization to learn and study the attitude and opinion or aims to change the technology, that is to change the socio economy of the community.

The special modernization definition refer to the underdeveloped society to and depicting their effort to run after the underdevelopment from the developed society to live side by side with them in the same historical period in the global community. With other word, modernization depicts the movement from the periphery to the core of modern society.

Table 3.2

Informant living standard after live in Surabaya

\begin{tabular}{|l|l|l|l|}
\hline No & $\begin{array}{l}\text { Condition after live in } \\
\text { Surabaya }\end{array}$ & Informant \\
\hline 1 & Unchanged & 36 & 48.65 \\
\hline 2 & Improved & 25 & 33.78 \\
\hline 3 & Decreased & 13 & 17.57 \\
\hline & Total & 74 & $100 \%$ \\
\hline
\end{tabular}

Why the respondent's living standard still unchanged after live in Surabaya, it is caused by the migration goals not to improve the economic/income but the interest to the urban culture that is more modern than at the rural area, expect to change the appearance and character so will not considered as old fashioned. 
While $17.57 \%$ informant experience the decreasing income after migrated to Surabaya in general when did the migration did not have the needed skills to get available jobs in Surabaya.

Each person or family has needs scale that is influenced by income. The income condition of individual will influence their consumption. The higher income then the higher amount of good that will be consumed. If the consumption want to be increased while the income is unchanged then the saving will be used, then the saving will decrease.

In general, it can be said that the facing problems in the society come from the unlimited needs. Usually people never satisfied with the goods they obtain and achievement they get. If the past desire and needs have been fulfilled then the new desires will emerge. In the poor country it is normal. Food consumption still low and housing less sufficient that encourage the society to reach higher living standard.

Table 3.3

Criminal case types done by informants

\begin{tabular}{|l|l|l|l|}
\hline No & Criminal case types & Amount & $\%$ \\
\hline 1 & Theft & 24 & 32.43 \\
\hline 2 & Drugs & 13 & 17.57 \\
\hline 3 & Gambling & 21 & 28.38 \\
\hline 4 & Murder/abortion & 2 & 2.70 \\
\hline 5 & Threat & 1 & 1.35 \\
\hline 6 & Counterfeit money & 1 & 1.35 \\
\hline 7 & Rape & 2 & 2.70 \\
\hline 8 & Embezzlement & 3 & 4.05 \\
\hline 9 & Cold steel & 1 & 1.35 \\
\hline 10 & Deception & 3 & 4.05 \\
\hline 11 & Selling pirated VCD & 1 & 1.35 \\
\hline 12 & Molestation & 2 & 2.70 \\
\hline & Total & 74 & $100 \%$ \\
\hline
\end{tabular}

Source: Processed data, 2012

Many possibilities that become the causing factors as background for someone do bad or deviant things. Because of that, also with the informant behavior, there are some things that become motives or background. Based on the results, in outline there are 3 causing fact ors that is economic factor (get money/goods), environmental factors or get on bandwagon (filling the spare time), leisure factor (want to feel drugs), and personal factor (dissatisfied feeling)

In the case motorcycle theft, informants do criminal actions because of getting bandwagon when they work for building construction. He just get on bandwagon or imitate what his friend do, it is recognized frankly that all the things are done in enjoy.

In the case of drug usage, the background for doing the action is the enjoyment factor only and done to get spirit satisfaction.

From the table 3.3 above, the crime types that done by informant such as: theft $(32.43 \%)$, gambling $(28.38 \%)$, drug $(17.57 \%)$, embezzlement $(4.05 \%)$, deception $(4.05 \%)$, rape $(2.70 \%)$, molestation $(2.70 \%)$, murder/abortion $(2.70 \%)$, threat $(1.35 \%)$, counterfe it money $(1.35 \%)$, cold steel $(1.35 \%)$, selling the pirated VCD (1.35\%). From the eleven crimes done by the informants, the economic motives still dominate the done crimes.

Economic factors as the results shown become the dominant factors for the criminal action emergence. From the results, the informant benefit after doing the crime to get money/goods $(70.27 \%)$, fell the spare time $(5.41 \%)$, wan to feel the drugs $(8.11 \%)$, and dissatisfied $(16.22 \%)$ do murder and molestation. Not little from the informant that do the crime for their economic income. In the economic situation like now, where the competition in a very field is very strong, the economic factors should become the goals that want to be reached for everyone especially for the informant, to support their welfare.

Motivation to do crime in general, to get money or economic needs. The economic model for the crime is standard model from the decision making where individual select between criminal activities or legal activities based on utility expectation for each activity. It can be assumed that the involvement in the criminal activities is the results of individual optimization behavior to incentives.

Among various factors that influence the individual decision to involve in the criminal activities is (1) benefit expectation from the crime or wage from the legal work (2) risk to be caught and prosecuted, (3) the punishment time, and (4) opportunities in the legal activities. 
The risks that are felt by informant when caught by the police, they regretted their actions with various disadvantages: pass on their family $(8 / 11)$, do not work $(63.51 \%)$, moral disadvantages $(2.70 \%)$, get prison punishment $(18.29 \%)$, and separated from the family $(18.92 \%)$.

By determining an equation to get incentives in decision to do crimes is the natural initial step in analyzing for the crime as model that is important from all the things is reward that is relative from the criminal activities and legal activities. For example, economic model look at the criminals doers in doing criminal action if the benefit expectation from the criminal activities more than the legal activities.

Crime is the results of negative deviant behavior that able to endanger individual interest of societies and state that disturb order and security in the society. The informant motives to do crime such as a) to fulfill economic needs when do not work in the case of theft $(18.92 \%)$ b) entertain themselves in the case of drug and gambling (5.41\%) c) add working spirit in case of drug $(5.41 \%)$, d) get additional money by selling togel gambling $(27.02 \%)$ e) do for fun to use drug $(8.11 \%) \mathrm{f})$ constrained to get becak passenger they are ordered to by togel number and stealing $(2.70 \%) \mathrm{g}$ ) spontaneity / revenge in case of theft, murder, threat, molestation $(6.76 \%) \mathrm{h}$ ) get on bandwagon when steal motorcycle and drug $(9.46 \%)$ i) unaware to do motorcycle seizure $(1.35 \%) \mathrm{j}$ ) abortion because the girlfriend want to continue the national test $(1.35 \%) \mathrm{k}$ ) evil desire to do rape $(2.70 \%)$ i) tighten the friendship of togel gambling and drug (4.06\%) m) adding sexual satisfaction with drug (2.70\%) o) finding profit from the selling of pirated VCD (1.35\%), p) to pay boarding house fee $(1.35 \%)$ q) trapped in dept in case servant stealing the employer goods $(1.35 \%)$

The economic factors as research results shown is the dominant factors for the criminal actions. In the economic situation like this, where the competition is intense, economy become one of goals to be achieved by everyone especially for women. In effort to reach the goals, sometimes with good and honest way, but some also do with short cut way, and become the criminal doers.

The reality in line with the criminal cause theory. According to the socialist thought, that the crime emerges because the economic pressure. Someone become bad when be trapped in the economic problems, such as poor, unemployment, employment termination.

The differences between poor and rich is the economic symptoms, and also with the differences between entrepreneurs, job, labor, unemployment also the economic symptoms too. The differences sometime are very prominent cause the tension in the societies, conflict so produce crime.

In the explanation of above case, it is found that there are some one that do the drug abuse because of the enjoyment fulfillment. For them, the actions just to fulfill their satisfaction.

The causing factors is the presence of high biological encouragement, and also become the part of internal factor. Libido of husband make him doing something against the law as stated by Sudarto, that "criminality come from the imbalance between desire (libido) and the satisfaction possibility"

Each normal economic model stated that the crime depend on (1) legal and illegal opportunities (2) possibility to be caught and (3) punishment level, in the terminology of Richard Freeman in "The Economics of Crime" (1999) at Handbood of Labor Economics, they concerned about intrinsic. So, hard punishment and the improvement of work opportunities of the criminal doers should be improved together to decrease the crime. Of course, it assumes that crime and job are determined by similar factor and that the higher income from the legal business improve the job opportunities. Initial work implemented the model of time period allocation that is static to analyze the criminal actions. With other word, crime and work are considered as substitute activities, if individual allocates more time for work, he will has less time to do crime because he has less time to do that. The basic economic model of crime is static or comparative-static in the economic jargon because do not consider the criminal doer that is potentially consider more than one time period in taking decision.

In the human being life, the criminal actions always present and will not conclude when there is gap in the social life of the society, but the modus that always changes suitable with the dynamic life. So crime can be occurred because it is influenced by the milieu of someone. It can be proven from the research, that informants that do criminal because of supported by others of $83.78 \%$, informants that do the criminal action because of self support of $13.53 \%$, while the remain of $2.70 \%$ do the criminal action because of the family support.

From the results, the informant quantity that do first crime of $71.62 \%$, that do the crime $2-5$ times of $18.92 \%$, that do crime $6-10$ times of $6.76 \%$, while that do more than 11 times of $1.35 \%$.

Crime that done by family, because family is the place for the personality formation, internalization, where people learn good or bad. If the internal and external control is weak, 
alternative to reach the goal is limited, then there will be delinquency, it is something that occurred rarely. Human being is given control so do not do violation, because of that adequate socialization process will decrease the delinquency. Because, in here the education process is done to someone that taught to control the impulse. Beside that, the internal and external control should be strong, and also strong law abiding.

\section{Socio economic condition of the criminals after migrated to the Surabaya city}

The factors at the original place of migrant or at the destination can be negative or positive factors. The factors at the original place of the migrant can be the factors that encourage to go out or not. At the destination the factor can be in the form of attracting force so someone want to come or reject someone to come. The infertile land, low income at the original place of migrant become the encouragement to move. But the tight clannish, compact social environment become the restraints not to move.

High wage, interesting job opportunities at the destination become the attracting factors to come there but uncertainty, facing risk, uncertain land ownership and etc become the inhibiting factors to move to the migrant destination. The long distance, unclear information, non smooth transportation, bad bureaucratization are the inhibiting factors. At other side, there is information about easiness, such as transportation easiness and others become the supporting factors.

The results showed that informant stated various reason to move to the Surabaya city as follow: living standard improvement / job finding / earn the life/ try fortune (67.57\%), follow the husband/wife $(10.82 \%)$, follow parents $(9.46 \%)$, for proper living $(4.05 \%)$, low income in the village $(2.70 \%)$, take care for the schooling children $(1.35 \%)$, for business $(1.35 \%)$, for study $(1.35 \%)$, follow the children $(1.35 \%)$

The area that will be the destination in doing urbanization usually is big city with high density and developed either in economy or education. Society determine the destined area not only based on the their own thought or will, but in general come from the strong influence. The influence usually in the form of allurement that come from the around persons that do urbanization before, information in media about the destined place, personal dream, pressure of economic needs, and etc. The influences usually come from the original area to encourage the society or the destination that become attractive power for the societies to do urbanization.

The results showed that the factors that influence the informant to move to Surabaya such as : parent $(33.78 \%)$, friend $(24.32 \%)$, husband/wife $(22.98 \%)$, relatives $(12.17 \%)$, children (4.05\%), others (2.70). Encouragement from around person that do urbanization before that encourage the informants to the urbanization to Surabaya.

After move and domicile in Surabaya, the respondent endure to live there because have enough wealth. The wealth such as motor cycle, house, saving, etc. Data from table 5.31 above, informants that have motorcycle $35.13 \%$, houses $27.03 \%$, saving $18.91 \%$, and $14.86 \%$ informants have other wealth such as small shop, shop, catering business, laundry etc.

One of the ways to value the welfare improvement of the population in country or area by looking at the income per capita of the population. The higher income per capita the higher welfare and purchasing power of the population.

\section{The relationship between socio economic factors of migrant with the criminal actions}

From the explanation above, the socio economic factors of migrant such as:

a. From the age, criminal doer of 25-40 years old, it showed that they are considered as mature and productive when be viewed from the manpower. Mature in this case they have family, and male, and required as the family head, that give earning for the family member prosperity.

b. The criminal doers are dominated by Javanese and maduranese ethnic with education level of elementary school, junior high school, and senior high school.

c. The respondent religions mostly islam and Christian, with their belief level to pray of $47.30 \%$, seldom to pray $13.51 \%$, while the remain $39.19 \%$ with moderate belief level.

d. Economic status of respondent of $89.18 \%$, with income less than $\mathrm{Rp} 1.000 .000$ with work type of porter and trader. It influence to the family prosperity with the dependents of 3-4 persons.

e. The crime types that mostly done by respondent, such as theft, drug, and gambling. The criminal behaviors bring much benefit from economic side

f. Motivation to do the crime to get money and to fulfill other economic needs. 
g. Reason to migrate to Surabaya because want to improve the living standard or economic improvement.

\section{Conclusion And Recommendations}

The socio economic condition of the criminals after migrated to the Surabaya city still constant with reason because interested in the more modern urban culture and want to be appeared as urban persons, while migrant with increasing welfare because higher income. While migrants with decreasing welfare because they do not have skill to get job.

Socio economic factors of migrants that impact the criminal behaviors because the graduate of Junior high school / aliyah is not vocational education so do not have skill when doing work, crime can not be determine by the living period in Surabaya city but because of the disappointment in reaching the welfare, the criminal behavior do not consider the religious precept and the pray intensity, the moderate job sustainability with less income, the difficulty to get job because the less work place availability, intense competition, many dependents out of family, and influenced by the someone milieu.

The criminal motives such as : get additional money by selling togel gambling, fulfill the economic needs when do not work in case of theft, get on bandwagon when do the motorcycle theft and drugs, get on bandwagon in drug, spontaneity / revenge in case of theft of family /murder/threat/molestation, self entertainment in case of drug and togel gambling, add working spirit in case of drugs use, tighten the friendship in the togel gambling and drugs, evil desire to do rape. Constrained to get becak passenger be ordered to buy togel gambling and steal. Add sexual satisfaction with drug, unaware in doing motorcycle seizure, find profit by selling pirated VCD, trapped in debt for case the servant steal the employer goods.

The criminal action always present and will not conclude during there is social gap in the societal life, only the modus that changes suitable the dynamic life. So the crime can be occurred because influenced by the someone milieu. Those that support the criminal action: others $83.78 \%$, self $13.53 \%$, and family $2.70 \%$. The quantity of criminal action: once $71.62 \%, 2-5$ times $18.92 \%$, 610 times $6.76 \%$, more than 11 times $1.35 \%$.

The reason to migrate to the Surabaya: to increase living standard/ job finding / job finding / earn the life/ try fortune $(67.57 \%)$, follow the husband/wife $(10.82 \%)$, follow parents $(9.46 \%)$, for proper living $(4.05 \%)$, low income in the village $(2.70 \%)$, take care for the schooling children $(1.35 \%)$, for business $(1.35 \%)$, for study $(1.35 \%)$, follow the children $(1.35 \%)$

The wealth that make them endure to live in Surabaya: motorcycle $35.13 \%$, houses $27.03 \%$, saving $18.91 \%$, and $14.86 \%$ informants have other wealth such as small shop, shop, catering business, laundry etc. The reason to migrate to Surabaya: :iving standard improvement / job finding / earn the life/ try fortune, follow the husband/wife, follow parents, for proper living, low income in the village, take care for the schooling children, for business, for stud, follow the children. Decision to migrate is influenced by: parent $(33.78 \%)$, friends $(24.32 \%)$, husband/wife $(22.98 \%)$, relatives $(12.17 \%)$, children $(4.05 \%)$, etc $(2.70 \%)$.

\section{SUGGESTION}

a. Modern culture and urban life today become the goals to migrate to the Surabaya city, then it is suggested to the city government of Surabaya to do limitation for the enter of new comer, with socialization that the modern urban life able to grow out of Surabaya.

b. Give suggestion to the education agency to give skill curriculum for Senior High School/ Aliyah that do not continue to the higher education, so the graduate of Senior High School / Aliyah have sufficient skills to work.

c. Suggestions to the government through Department of Religion to increase the speech about the improvement of belief to God, so people will afraid to go to hell if doing criminal action.

d. The criminal actions always present and will not conclude when there is gap in the social life of the society, but the modus that always changes suitable with the dynamic life. So crime can be occurred because it is influenced by the milieu of someone, either other people or family, to be suggested to increase extension about the importance of education and to build good family.

e. To overcome the crime, the Indonesian Police should cooperate with self security parties, to increase patrol continuously.

f. To increase the living standard by trying fortune in the urban area today can be inhibited by giving skill education, so people do not need to migrate to sell their work (production). 
The government should give smoothness of traffic for goods and services to bridge between urban and rural area.

\section{References}

[1]. Putnam, R. 1995. The Prosperous Community Social Capital and Public Life, American Prospec (13): 35-42 (In The World Bank. 1998 5-7).

[2]. Todaro, Michael P. 1976. Migration in Developing Countries, Publication of Hirchmann, Charles, 1958. Migrationverket, Evans.uw.edu/.../Hirschman (downloaded on 30 November 2013)

[3]. Sutherland, Edwin, 1981, White Collar Crime, en.wikipedia.org/wiki/Edwin_Sutherland, downloaded on 30 November 2013.

[4]. Atmasasmita, Romli (2005). Theory and Capita Selecta of Criminology”, Revised Edition of Second Edition by PT Refika Aditama - Bandung.

[5]. Hagan, John, 1998. Power Control Theory, Knowledge. Sagepub.com, Downloaded on 30 November 2013

[6]. Rahardi, 2012. Meaning of Modernization, http://coco-jkrahardi.blogspot.com. Downloaded on 30 November 2013. 